Frédéric BOURDIER, Sexualité et sociabilité en Inde du Sud. Familles en péril au temps du Sida

Paris, éd. Karthala, 2001, 138 pages

Anne Viguier

\title{
CpenEdition
}

Journals

Édition électronique

URL : http://journals.openedition.org/clio/9777

DOI : 10.4000/clio.9777

ISSN : 1777-5299

Éditeur

Belin

Édition imprimée

Date de publication : 1 mai 2010

Pagination : 320-323

ISSN : $1252-7017$

Référence électronique

Anne Viguier, «Frédéric boundien, Sexualité et sociabilité en Inde du Sud. Familles en péril au temps du Sida », Clio. Femmes, Genre, Histoire [En ligne], 31 | 2010, mis en ligne le 21 juin 2010, consulté le 10 décembre 2020. URL : http://journals.openedition.org/clio/9777 ; DOI : https://doi.org/10.4000/clio. 9777

Ce document a été généré automatiquement le 10 décembre 2020.

Tous droits réservés 


\title{
Frédéric BOURDIER, Sexualité et sociabilité en Inde du Sud. Familles en péril au temps du Sida
}

\author{
Paris, éd. Karthala, 2001, 138 pages
}

\section{Anne Viguier}

\section{RÉFÉRENCE}

Frédéric BOURDIER, Sexualité et sociabilité en Inde du Sud. Familles en péril au temps du Sida, Paris, éd. Karthala, 2001, 138 pages.

1 Frédéric Bourdier est un anthropologue, docteur en géographie tropicale et membre de l'équipe CNRS «Sociétés, Santé, Développement ». Son livre est l'aboutissement d'une enquête de deux ans et demi financée par l'ANRS (Agence nationale de recherche sur le Sida) et confiée au laboratoire CNRS en 1994. Une équipe pluridisciplinaire (ethnologues, géographes, psychosociologues, membres d'ONG) composée d'universitaires, d'étudiants indiens, de responsables dans le secteur de la santé et d'enquêteurs s'est constituée en 1996. L'auteur était chargé d'animer la recherche dans trois villes (Chennai - ancienne Madras -, Coimbatore et Madurai) du Tamil Nadu, un État du sud de l'Inde. Le but était d'étudier les pratiques qui pouvaient contribuer localement à l'exposition au virus, à une époque où l'on parlait peu du sida en Inde. Les enquêtes articulées mais indépendantes furent menées en deux phases, l'une relevant de sciences sociales (ses résultats sont produits dans ce livre), l'autre de l'épidémiologie. Les stratégies d'approche dans les enquêtes réalisées sur vingt-six micro-sites relèvent du quantitatif (analyse de 10000 annonces maritales, enquête socio-familiale par questionnaire auprès de 896 personnes) et du qualitatif (récits de vie recueillis auprès de 104 personnes dont sept sont présentées en détail dans le chapitre 5). Des efforts systématiques ont été faits pour recouper les informations avec celles 
données par d'autres membres de la famille. Parmi les 896 interviewés, 453 étaient célibataires, 117 vivaient dans le milieu de la prostitution.

2 Les études sur la sexualité et les pratiques sexuelles en Inde sont rares en dehors du champ strictement médical. La norme et le discours établi enferment la sexualité dans l'organisation sociale du mariage. Hiérarchie et séparation des castes, monogamie, voie ascétique prônée en dehors du mariage... L'Inde s'est d'abord vue comme protégée du sida par le supposé respect de ces principes intangibles. L'approche de l'ethnologie classique est restée souvent dépendante de l'indologie qui se réfère avant tout aux écritures sacrées. D'où l'intérêt d'une étude qui évoque ce que l'on observe et non ce qui devrait être.

3 Rappelons qu'en Inde la sexualité hors mariage est perçue comme une déviance. C'est une transgression que l'on explique par une incapacité à se contrôler, propre à des populations considérées comme marginales. Les trajectoires sexuelles sont censées coïncider avec les normes morales. La débauche et les pérégrinations sexuelles sont confinées essentiellement dans un passé commémoré par le traité Kamasutra et les sculptures érotiques des temples hindous et, au présent, dans les red light areas (zones de prostitution visible des villes). Pourtant les sociétés hindoues traditionnelles acceptaient, semble-t-il, une multitude de pratiques sexuelles. Courtisans transsexuels, danseurs de la tradition devadasi (prostitution sacrée dans les temples), danseurs des rues, chanteurs et musiciens apportaient plaisir et sensualité. Les cultures hindoues ont subi d'abord la pression des enseignements bouddhistes et jaïns prônant la renonciation physique et sexuelle. À l'époque de la domination moghole, la sexualité fut reléguée sous le purdah (la réclusion des femmes) et les femmes éloignées de la sphère publique. La colonisation britannique et ses efforts évangélisateurs visant à " civiliser » des indigènes "à la sexualité exotique ", accentuèrent encore la rupture avec les mœurs sans doute plus libres d'antan.

4 L'enquête présentée par F. Bourdier montre que si la norme est souvent acceptée dans les discours des personnes rencontrées (les célibataires trouvent le système cohérent et sécurisant), de nombreuses pratiques « déviantes » existent et pas seulement en dehors du mariage. Le choix des enquêteurs était de se pencher en priorité sur des situations de mobilité spatiale et les processus qui engendrent des exclus et des déchus du mariage. Ils s'interrogeaient en priorité sur les formes de refus, de déviance, de marginalité et d'exclusion à l'égard des formes d'alliance traditionnelles, qui peuvent contribuer à l'exposition au virus. Mais le caractère sacré de l'union et l'indissolubilité du couple n'impliquent pas l'absence de relations hors mariage. La famille et le système des castes se révèlent aussi facteurs de désordres, à cause de l'importance des délais de mariage mais aussi de l'existence admise ou cachée de la bigamie ou de la polygamie.

De nombreux individus mariés subissent les soubresauts d'une union indésirable (presque toujours dans le cadre d'un mariage arrangé). Les relations hors mariage existent pour les hommes (surtout ceux qui sont amenés à une mobilité spatiale comme les camionneurs) mais aussi pour les femmes. Les personnes mariées sont recherchées par les jeunes célibataires en quête d'une expérience qui ne compromette pas leur situation sociale. À l'intérieur des familles, les incestes ne sont pas rares, entre cousins ou entre l'oncle et sa nièce. La prostitution est très répandue, et pas seulement dans les zones rouges surtout fréquentées par des bandes de jeunes hommes célibataires. Des femmes, souvent à la suite d'une dette non payée, sont contraintes à la prostitution occasionnelle (cachée à leur famille). L'homosexualité aussi paraît répandue, même si la 
plupart des homosexuels sont mariés. Le livre évoque le cas particulier des hijras (alis au Tamil Nadu), qui disent n'appartenir ni à la catégorie des hommes ni à celle des femmes et représentent une troisième catégorie sexuelle qui tendrait vers la féminitude. La sexualité constitue un aspect important de leur vie dont la plupart ne se cachent pas. Certains sont castrés, d'autres non. Les alis vivent en communauté de « sœurs » autour d'un leader (guru) et se prostituent occasionnellement, souvent à l'insu du leader. La quête d'un partenaire stable est cependant une de leurs préoccupations majeures. Elles tombent souvent amoureuses d'un homme qu'elles fréquentent régulièrement et elles aspirent à vivre en couple, voire à se marier.

6 L'enquête ne portait pas sur le détail des pratiques sexuelles (en dehors de l'utilisation du préservatif) ni sur la notion de plaisir sexuel ou les attentes sexuelles des personnes interrogées. L'auteur donne cependant quelques indications sur la manière dont les Tamouls perçoivent l'échange sexuel. Tout Tamoul redoute la sakti féminine et sait que le pouvoir de création de la femme ne se limite pas à sa possibilité d'enfanter. Ce pouvoir de création qui assure la bonne marche et la bonne santé des membres de sa famille se double d'un pouvoir de destruction qui la rend dangereuse. Mais ce fond culturel vient surtout de sources écrites. Dans la réalité, on constate la fréquence de la violence physique et psychologique infligée aux femmes. La vie maritale s'assimile à un acte de violence symbolique et tangible pour la jeune épouse. Cette violence est aussi censée donner davantage de plaisir à l'homme.

7 Contrairement à certaines idées reçues, les jeunes gens ont des connaissances parfois étendues sur la sexualité. Des informations circulent par le biais de la littérature jaune (revues qui touchent un large public et décrivent le déroulement minutieux de l'acte sexuel), des films bleus (films érotiques ou pornographiques qui circulent ou sont projetés au milieu de séances plus anodines pour un public exclusivement masculin). Dans les slums (bidonvilles), la promiscuité est grande et le vocabulaire cru et précis. L'ignorance domine surtout parmi les jeunes filles de haute caste étroitement surveillées avant leur mariage.

8 Au sein du mariage, la sexualité est contrôlée. La nuit de noces suit un protocole précis, surveillé souvent par la belle-mère (décrite dans un récit de vie). Les interdits sexuels se calquent sur le calendrier religieux et le nombre de jours autorisés par mois est tout au plus une dizaine les mois fastes. En pays tamoul, il existe une équivalence entre le sang et le sperme. L'acte sexuel est un échange de sang (le sperme étant un concentré de sang). Le sang de l'homme pénètre le sang de la femme par le sperme. Dans l'acte sexuel, l'échange de fluide bénéficie au partenaire le plus âgé. D'où la recherche par des hommes âgés de jeunes pucelles qui les protègeraient aussi des maladies. Les relations sexuelles non contrôlées sont censées apporter un affaiblissement du corps. Il en est de même d'ailleurs pour la masturbation. Comme la prise de nourriture, l'acte sexuel n'est jamais anodin. Non contrôlé, il peut mettre en péril l'équilibre familial et la santé des proches.

9 Le livre dévoile un tableau assez noir d'une société où les tabous et l'organisation sociale génèrent des frustrations et des souffrances considérables. Il est vrai que l'enquête se concentrait sur une population "en marge ", en situation de mobilité ou de rupture. Se refusant à une stricte neutralité, l'auteur, qui a parfois été amené à aider des personnes en situation de détresse, refuse de croire que les compensations souvent avancées (par exemple, le rôle de l'alimentation comme dérivatif, notamment pour les femmes) suffiraient à maintenir une stabilité sociale. Les concepts d'hétéroculture et 
d'identité cumulative, traduit par un processus d'empilement des façons d'être, s'avère approprié pour expliquer la manière dont les jeunes Indiens vivent les contradictions entre la norme sociale et une sorte de " propagande sexuelle » véhiculée par les médias.

10 Cet ouvrage nous ouvre un accès inédit sur les pratiques contemporaines en Inde du sud, qui contrastent avec le discours ou les écrits auxquels on peut plus facilement recourir. Les historiens « de l'Ouest » auraient probablement avantage à s'intéresser à ce domaine culturel afin d'évaluer dans leur propre documentation la part du dit et du non-dit. 